\title{
A summary of the National Forum's Review of the Existing Higher Education Policy Landscape for Digital Teaching and Learning in Ireland
}

\author{
Dr. Tony Murphy \\ National Forum for the Enhancement of Teaching and Learning in Higher Education \\ Dublin, Ireland \\ Dr. Terry Maguire \\ National Forum for the Enhancement of Teaching and Learning in Higher Education \\ Dublin, Ireland
}

(C) Tony Murphy and Terry Maguire. This work is licensed under the Creative Commons Attribution-NonCommercial-ShareAlike 4.0 International License. To view a copy of this license, visit https://creativecommons.org/licenses/by-nc-sa/4.0/ .

\begin{abstract}
This summary outlines the findings that emerged from the National Forum's project on higher education policy and the challenges and opportunities posed for teaching and learning by digital technology. The project sought to define whether existing policies were enabling and reflected the language of digital teaching and learning. The summary discusses the findings within the wider context of a national and international drive toward utilising digital technology to facilitate a more flexible learning environment.
\end{abstract}

Keywords: Ireland, Higher Education, Digital, Technology, Teaching, Learning

The use of digital technology has changed the environment of teaching and learning in higher education. Practitioners often find themselves making decisions in situations that did not arise in a pre-digital teaching and learning context. These changes include more collaboration and sharing, increased deliberation and clarification regarding the nature of relationships with outside agents, more opportunities to use student generated content and the ethical issues around the use of recorded content from active sessions with students.

Policy development is critical to supporting digital teaching and learning and in driving change (Gregory and Lodge, 2015). Further, policy can aid decision making, provide direction, and bring coherence across different stakeholders (Garrison, 2011).

The High Level Group on the Modernisation of Higher Education recommended that national guidelines should be developed for 'ensuring quality in open and online 
learning, and to promote excellence in the use of ICT in higher education provision' (2014, p. 40). The uptake of digital and online learning technologies has been characterised as uneven across the $\mathrm{EU}$, and a lack of coherent policy frameworks is seen as one of the main barriers to mainstreaming (European Commission, 2016). A recent survey of European member states found that approximately one third have national policies for digital and online learning either in place or being implemented (European Commission, 2016).

The national outlook on policies for digital teaching and learning can be viewed within the context of the National Strategy for Higher Education to 2030 (Department of Education and Skills, 2011) and the Higher Education System Performance Frameworks (Higher Education Authority, 2016; 2018). Both emphasise the increasing demand for flexible learning opportunities, part-time, work-based learning and short intensive skills programmes, and the need for strategy development in this area in higher education.

Attempts to accommodate digital teaching and learning without appropriate policy frameworks has allowed practices to emerge within Irish Higher Education Institutions (HEls) that have the potential to lead to inefficiencies and/or confusion among staff and students. These include:

- Requiring physical rooms to be booked for an online tutorial because the timetable is governed by the room booking application.

- Teachers being required to submit grades both electronically and by hand.

- Teachers using third-party platforms for teaching, learning and assessments independently of the $\mathrm{HEI}$, resulting in an absence of institutional technical support in the event of something going wrong with a platform.

- Informal approaches to seeking permission to record participating students and staff or use student content.

- Ownership of content being determined on a case-by-case basis, influenced by employment contracts rather than HEI policy.

- Challenges in verifying student identity in assessment and participation in distance learning or technology-enabled assessment contexts.

The National Forum's Digital Roadmap provided a framework for embedding a digital dimension in teaching and learning policies in Ireland. A nationally coordinated project was completed to examine the current policy framework for digital teaching and learning in Ireland. Informed by a scoping group with representation from students, teachers, senior managers, policy makers the project reviewed the current status of policies across the sector. The project was guided by a terms of reference agreed by the scoping group (National Forum, 2018a).

This paper provides a brief synopsis of the findings from that review. The full report Review of the Existing Higher Education Policy Landscape for Digital Teaching and Learning in Ireland is available on the National Forum website at www.teachingandlearning.ie. 
For the purposes of the review, policies were defined as mandated principles for guiding decision making by staff and students in a higher education institution. Documents were included in the review if they contained principles or standards intended to guide decision making that related specifically to teaching and learning. Consultation with staff and students across the sector highlighted a need for policies for higher education which enable staff to practice enhanced teaching and learning in an atmosphere of consultation, innovation and strategic alignment. Through discussion, it was agreed that enabling policies are defined as those which are implementable, situated in practice and reflective of the priorities of the HEI. Table 1 outlines the criteria which determine whether a policy can be considered enabling.

Table 1: Criteria for determining if a policy is enabling (National Forum, 2018a)

\begin{tabular}{|l|l|}
\hline $\begin{array}{l}\text { In order for a policy to be deemed } \\
\text { implementable it needs to: }\end{array}$ & $\begin{array}{l}\text { - clearly define the HEI's commitment to the policy area } \\
\text { - have an implementation plan } \\
\text { be accompanied by policy instruments such as procedures, and clearly defined areas of } \\
\text { responsibility }\end{array}$ \\
\hline $\begin{array}{l}\text { In order for a policy to be deemed } \\
\text { situated in practice it needs to: }\end{array}$ & $\begin{array}{l}\text { - be based on consultation } \\
- \text { have been tested at operational level } \\
\text { - be routinely monitored and reviewed for effectiveness }\end{array}$ \\
\hline $\begin{array}{l}\text { In order for a policy to be deemed } \\
\text { reflective of the HEl's priorities it } \\
\text { needs to: }\end{array}$ & $\begin{array}{l}\text { - be guided by the HEl's vision } \\
\text { - be in line with the HEl's strategic objectives }\end{array}$ \\
\hline
\end{tabular}

When existing policies were reviewed through the lens of the enabling criteria outlined above, in terms of how enabling policies were, what emerged was a sense that policies scored highest at being implementable (46\% of criteria met), then second at being reflective of $\mathrm{HEI}$ priorities ( $43 \%$ of criteria met) and then third at situated in practice ( $22 \%$ of criteria met). Collectively, only $35 \%$ of criteria were met across the reviewed documents. The content analysis indicated that the keywords and phrases used to describe the issues and opportunities of digital teaching and learning were not often reflected in institutional policies. For example, digital footprint, code of practice or code of conduct were mentioned in 36 of the reviewed policies, but none of the policies had been designed specifically to address students' digital footprint/wellbeing, and while the terms social media or social networking were found 162 times across 16 documents, these terms were rarely used in conjunction with the words teaching or learning. Under the heading of assessment, only nine of 66 documents retrieved that referred to assessment contained a mention of assessment near the words electronic, online or digital, and there was a noted absence of mentions of the phrase technologyenabled assessment.

The review also revealed that the lack of appropriate policies that were situated in practice meant that informal practices around the use of digital technology for teaching and learning had emerged that were possibly not serving the needs of the staff, students of HEls. Reports of inconsistent, inefficient or informal practices surrounding the use of digital technology for teaching and learning is not uncommon, especially 
given that the use of digital technology tended to emerge informally from the teaching and learning experience. The review does, however, suggest that policies do need to be more situated in practice if they are to incorporate innovative practice that is responding to existing needs.

An acknowledgement by HEls of the need to examine their existing policies for digital teaching and learning also emerged from this review, as it was reported that a number of HEls were looking at their policies and asking whether or not they were fit for purpose, given the challenges and opportunities posed by digital technology. With that in mind, the National Forum has also produced the Guide to Developing Enabling Policies for Digital Teaching and Learning (2018b) which outlines eight steps to developing enabling policies. The guide also represents a number of the concerns with using digital technology as reported by practitioners during the review. These concerns are represented in the guide as a series of questions that policy developers can consider as they review their own policies to assess the extent to which they are both enabling, and reflective of, the opportunities and challenges of digital teaching and learning. The Forum hopes that, together, the Review and Guide will be of value to the development of a Higher Education Digital Transformation Framework, a key area of focus for the Higher Education Authority, and the development of policies at institutional level.

\section{Key Findings}

- The challenges and opportunities related to digital teaching and learning were not generally reflected in the language of existing policies.

- When institutions operate without a robust policy framework for digital teaching and learning, informal practices can emerge which are inefficient, confusing or risky.

- Enabling policies are characterised as those which are implementable, situated in practice and reflective of institutional priorities.

- Enabling policies are permissive rather than restrictive and are intended to aid decision making.

- Many existing policies do not adequately recognise the practice context within which they are situated.

- Many institutions reported being in the process of developing policies for digital teaching and learning.

\section{References}

Department of Education and Skills (2011) National strategy for Higher Education to 2030. Report of the Strategy Group. Dublin: Government Publications Office. Available at: http://hea.ie/assets/uploads/2017/06/National-Strategy-for-Higher-Education-2030.pdf (Accessed: 15 November 2018). 
European Commission (2013) 'Analysis and mapping of innovative teaching and learning for all through new technologies and Open Educational Resources in Europe'. European Commission. Available at: https://eur-lex.europa.eu/legalcontent/EN/TXT/PDF/?uri=CELEX:52013SC0341\&from=EN (Accessed: 15 November 2018).

European Commission (2016) 'Education and Training 2020 Highlights from the Working Groups 2014 - 2015'. European Commission. Available at: http://ec.europa.eu/assets/eac/education/experts-groups/2014-2015/group-highlights en.pdf (Accessed: 15 November 2018).

Garrison, D. R. (2011) E-learning in the 21st century: a framework for research and practice. 2nd ed. New York, NY: Routledge.

Gregory, M. S.J., \& Lodge, J. M. (2015) 'Academic workload: the silent barrier to the implementation of technology-enhanced learning strategies in higher education', Distance Education, 36(2), pp. 210-230.

Higher Education Authority (2018) Higher Education System Performance Framework 20182020. Higher Education Authority, pp. 1-34. Available at:

https://www.education.ie/en/Publications/Education-Reports/higher-education-systemperformance-framework-2018-2020.pdf (Accessed: 15 November 2018).

Higher Education Authority (2016) Higher Education System Performance Framework 20142016. Higher Education Authority, pp. 1-10. Available at:

http://hea.ie/assets/uploads/2017/06/DES-System-Performance-Framework.pdf (Accessed: 15 November 2018).

High Level Group on the Modernisation of Higher Education (2014) New modes of learning and teaching in higher education. Report to the European Commission. Luxembourg:

Publications Office of the European Union.

National Forum for the Enhancement of Teaching and Learning in Higher Education (2018a) 'A Review of the Existing Higher Education Policy Landscape for Digital Teaching and Learning in Ireland'. Available at: https://www.teachingandlearning.ie/publication/a-review-ofthe-existing-higher-education-policy-landscape-for-digital-teaching-and-learning-in-ireland-2/ (Accessed: 15 November 2018).

National Forum for the Enhancement of Teaching and Learning in Higher Education (2018b) 'Guide to developing enabling policies for digital teaching and learning'. Available at: https://www.teachingandlearning.ie/publication/guide-to-developing-enabling-policies-fordigital-teaching-and-learning/ (Accessed: 15 November 2018).

National Forum for the Enhancement of Teaching and Learning in Higher Education (2015) 'Teaching and learning in Irish education: A roadmap for enhancement in a digital world 2015-2017'. Available at: http://eprints.teachingandlearning.ie/4157/1/Digital-Roadmapweb.pdf (Accessed: 15 November 2018). 